\title{
State-of-the-art embryo technologies in cattle
}

\author{
P Lonergan
}

School of Agriculture, Food Science and Veterinary Medicine, College of Life Sciences, University College Dublin, Belfield, Dublin 4, Ireland

Over the past 30 years, basic and applied studies on classical and advanced embryo technologies have generated a vast literature on factors regulating oocyte and embryo development and quality. In addition, over this period, commercial bovine embryo transfer has become a large international business. It is well recognised that bovine embryos derived in vivo are of superior quality to those derived from in vitro maturation, fertilization and culture. Relatively little has changed in the techniques of producing embryos in vivo although there is increasing evidence of the importance of, for example, peripheral and follicular endocrine profiles for the subsequent developmental competence of the embryo. The in vitro production of ruminant embryos is a three-step process involving oocyte maturation, oocyte fertilization and in vitro culture. Only $30-40 \%$ of such oocytes reach the blastocyst stage, at which they can be transferred to a recipient or frozen for future use. We know now that the quality of the oocyte is crucial in determining the proportion of immature oocytes that form blastocysts while the post-fertilization culture environment has a major influence on the quality of the blastocyst. Use of sexed-sorted sperm in conjunction with in vitro embryo production is a potentially efficient means of obtaining offspring of the desired sex. Concerns regarding the use of sexed semen technology include the apparent lower fertility of sorted sperm, the lower survival of sorted sperm after cryopreservation and the reduced number of sperm that could be separated in a specified time period. Assessment of embryo quality is a challenge. Morphological assessment is at present the most popular method for embryo selection prior to transfer. Other non-invasive assessment methods include the timing of the first cleavage division which has been linked to developmental ability. Quantitative examination of gene expression is an additional valuable tool to assess the viability of cultured embryos. A substantial amount of evidence exists to demonstrate that the culture conditions to which the embryo is exposed, particularly in the postfertilization period, can have perturbing effects on the pattern of gene expression in the embryo with potentially important long-term consequences. Collectively, in vivo and in vitro studies support the notion that the environment of the embryo is critical for its future. The identification and characterization of the short-term effects of in vitro culture 
raises the question about long-term consequences and safety of assisted reproductive technologies. The impact of some of these technologies on animal production will be the subject of this review.

\section{Introduction}

Over the past 30 years, basic and applied studies on classical (superovulation, non-surgical recovery and transfer of cattle embryos) and advanced embryo technologies (in vitro embryo production, nuclear transfer, transgenesis) have generated a vast literature on factors regulating oocyte and embryo development and quality. In addition, over this period, commercial bovine embryo transfer has become a large international business; approximately 790,000 bovine embryos $(550,000$ in vivo-derived and 240,000 in vitro produced) were transferred in 2004, the latest year for which data are available (Thibier 2005).

Three different generations of embryo technology have been developed: (i) in vivo embryo production, (ii) in vitro embryo production and (iii) cloning by nuclear transfer and transgenics. The objectives of this review are to give the reader an overview of current technologies in a few selected areas of embryo technology and to discuss how such technologies may impact on animal production.

\section{Embryo Technologies and Genetic Improvement}

The rate of genetic improvement in most breeding programmes is controlled by four main factors: (i) the selection intensity, a measure of how choosy we are as breeders; the fewer animals we select based on their superior performance the faster the rate of genetic progress (ii) the accuracy with which we can predict the genetic merit of an individual animal; the greater the accuracy the greater the potential improvement (iii) the genetic variation in the particular trait in question; the greater the variation for a given trait the greater the scope we have as breeders to select animals which are far from the mean level of performance for the trait and (iv) the generation interval, a measure of how long it will take the selected animal(s) to contribute their superior genes to the next generation via their offspring. In domestic species this tends to be quite long ( 2 to 3 years). Coupled with these four parameters are the selection differential (the difference in performance in a particular trait between the selected animals and the overall group from which they are selected, clearly related to the selection intensity) and the heritability of the trait, the proportion of the superiority (i.e., the proportion of the selection differential) which, on average, is passed on to the offspring. Put another way, it is a measure of how much a trait is under genetic control or how similar offspring are to their parents in terms of performance in a particular trait.

Several reproductive biotechnologies can impact one or more of these parameters and in so doing improve the rate of genetic improvement (Fig.1). These include more established technologies such as artificial insemination and multiple ovulation embryo transfer (MOET) as well as newer technologies of in vitro embryo production, cloning and transgenesis (Georges \& Massey 1991; Lohuis 1995; Nicholas 1996; Cunningham 1999, Van Arendonk \& Bijma 2003; Galli \& Lazzari 2005). Advantages of MOET, for example, include higher female selection intensity and increased selection accuracy (more full and half-sib information). However, variability in individual animal response to superovulation and the low average number of transferable embryos recovered are still limiting factors. In vitro embryo production can potentially affect generation interval through its use on prepubertal donors; for example, modest success in the production of pregnancies from in vitro produced embryos derived from prepubertal calves has been reported (e.g., Taneja et al. 2000). 


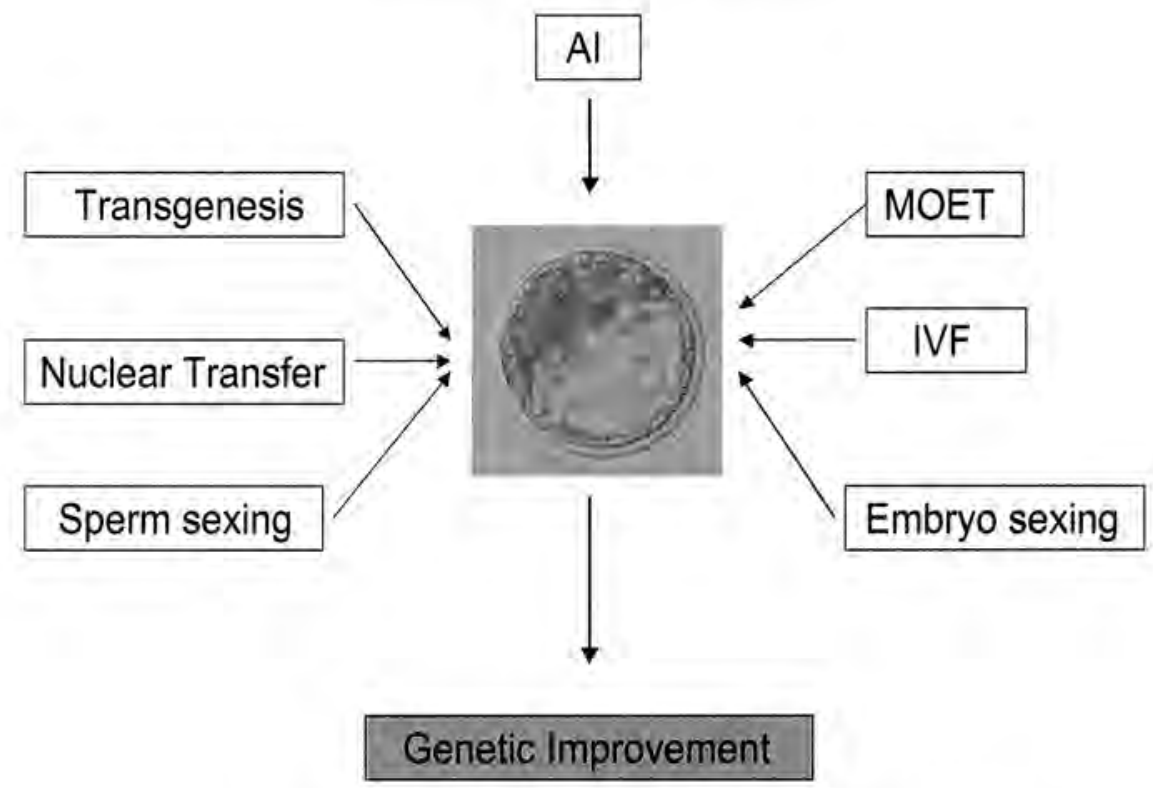

Fig. 1. The main reproductive technologies which can impact on the rate of genetic improvement.

\section{MOET}

Apart from artificial insemination, MOET is one of the longer established technologies impacting on animal breeding and reproduction. The techniques of MOET are well established and their use accounts for approximately $80 \%$ of cattle embryos transferred commercially (Thibier 2005). By increasing the reproductive rate of females MOET offers the opportunity to reduce the number of dams that need to be selected for the next generation while at the same time increasing the amount of information available on sibs for estimating breeding values. The biggest issue with respect to results is the huge variability in response of individual donors to superovulation. On average 4 to 6 transferable embryos are produced per treatment cycle, a yield which has not changed over the past 20 years (Hasler 2003); however, one-third of treated donors fail to respond, one-third yields 1 to 3 embryos and only the remaining one-third actually yields a significant number of embryos (Boland et al. 1991).

The maintenance of recipients is a major economic component of producing ET calves. If higher pregnancy rates are achieved by recipients, more efficient use of embryos would occur and financial savings could be realized through reductions in costs associated with transfer of embryos and maintenance of non-pregnant animals (Looney et al. 2006).

\section{Assessing embryo quality}

Embryo morphology assessment, with all its drawbacks, is at present the most widely used method for embryo selection prior to transfer for assisted reproduction in both domestic ruminants and humans. The high lipid content of ruminant embryos precludes the visualization of nuclear and nucleolar morphology in most cases, aspects which can easily be evaluated in the more transparent human or murine embryo. However, recent research focused on the correla- 
tion between bovine embryo morphology and ultrastructure, gene expression and cryotolerance, has provided evidence that much more can be deduced from morphological examination than previously thought (Van Soom et al. 2003). Morphological features such as colour of the blastomeres, the extent of compaction, kinetics of development and timing of blastocyst formation and expansion and diameter of the embryo at hatching can be linked with embryo quality. Other measures of embryo quality include non-invasive measures such as assessment of the timing of the first cleavage division after fertilization (Lonergan et al. 1999; Fair et al. 2004) and invasive measures such as examination of the pattern of transcript abundance in the blastocyst (Lonergan et al. 2003a,b; 2006).

In domestic species, there is a large body of evidence demonstrating that culture media can perturb gene expression in the developing embryo (see review by Wrenzycki et al. 2005). This is the case, not only when one compares in vitro and in vivo culture systems, but also when comparisons of different in vitro culture systems are made (see for example, Eckert \& Niemann 1998; Natale etal. 2001; Rizos et al. 2002b; Rinaudo \& Schultz 2004; Lonergan et al. 2003a;b; 2006). Apart from the culture medium used, the conditions of culture can also affect gene expression; bovine in vitro produced embryos respond to changes in oxygen concentrations by altering the expression of GLUT1 (Harvey et al. 2004) while in mice it has been reported that expression of GLUT1, GLUT3 and VEGF was significantly increased in embryos cultured under $2 \%$ vs 20\% oxygen (Kind et al. 2004). The prolonged period of postfertilization culture of the embryo presents both challenges and opportunities for manipulation of gene expression and thereby protein expression and phenotype which should be exploited in order to take account of the changing needs of the developing embryo.

\section{In vivo culture of embryos}

Culture of bovine embryos in the oviduct of the ewe has been shown by several authors to be a suitable environment for the development of embryos from the zygote to blastocyst stage (Lonergan et al. 2003a;b) and even through the early stages of elongation (Rexroad \& Powell 1999). Though not perfect, one advantage of this in vivo culture system is the ability to culture large numbers of embryos in a 'near in vivo' environment and in a cost effective manner. While the yield of blastocysts following such in vivo culture is not superior to that following culture in vitro, the quality of the blastocysts is significantly improved (Enright et al. 2000; Galli \& Lazzari 1996; Lazzari et al, 2002; Rizos et al. 2002a;b; Lonergan et al. 2003a;b).

Until the recent establishment and efficient application of endoscopy as a means of performing oviduct transfer and collection of embryos in cattle (Wetscher et al. 2005), in vivo culture of in vitro matured or fertilized embryos in the homologous bovine oviduct was extremely difficult. Techniques developed by Besenfelder and colleagues have focused on accessing the bovine oviduct to perform comparative in vivo versus in vitro studies and finally tubal transfer and flushing were combined for in vivo culture of IVP-derived embryos (Besenfelder \& Brem 1998; Besenfelder et al. 2001; Wetscher et al. 2005).

In vivo culture of zygotes derived by IVF could be one means of reducing the incidence of abnormally large offspring (Lazzari et al. 2002). Walmsley et al. (2004) examined the effect of transferring in vitro produced sheep embryos to recipient ewes on Day 2 versus Day 6 postfertilization on the incidence of oversized or abnormal lambs. Day 2 transfer of cleaved embryos did reduce but did not prevent the production of oversized or congenitally abnormal offspring that was likely attributable to the IVP system compared with transfer at Day 6. 


\section{Controlling gender}

Determination of the sex of the embryo prior to transfer would offer a clear advantage to the end-user and thereby add value to the product. Up until the early-nineties much of the focus on controlling offspring gender in practice was based on establishing the sex of the embryo, usually by biopsy, prior to transfer. This has potentially deleterious implications for the likelihood of a pregnancy ensuing.

A number of recent reviews have addressed the use of sexed semen in cattle and sheep production (Seidel \& Garner 2002; Seidel 2003a;b; Wheeler et al. 2006; Maxwell et al. 2004; Evans et al. 2004). While not an 'embryo technology' per se, the use of sex-sorted sperm in embryo production has massive potential for increasing efficiencies of animal production. Some of the concerns associated with the use of sexed semen include lower pregnancy rates, lower survival of sorted sperm after cryopreservation and number of sperm separated per unit time.

Numerous field trials have been conducted with single-ovulating heifers with fertility of low doses of sexed semen being about $60-90 \%$ of conventional doses of unsorted semen. The importance of heifer management to achieving comparable pregnancy rates has been highlighted (Seidel 2003b).

It is often the combination of two or more, rather than individual, technologies that make the biggest impact on practice. One appealing attribute of using sorted semen for in vitro embryo production is that much fewer sperm are need for IVF. Over the past decade or so sorted semen has been used for the production of embryos in vitro in both cattle (Lu et al. 1999) and sheep (Hollinshead et al. 2004; Morton et al. 2004).

For the dissemination of superior genes the use of sexed semen on superovulated donors of high genetic merit is desirable. In the study of Schenk et al. (2006), the number of embryos recovered from superovulated donors bred with sexed sperm was lower than that for donor females bred with non-sexed semen. However, the use of $20 \times 10^{6}$ sexed sperm per insemination dose resulted in similar numbers of transferable embryos of the desired sex compared to that for non-sexed sperm. Thus, use of sufficient numbers of sexed sperm in bovine superovulation and embryo transfer programmes can result in the production of more embryos of the desired sex with about half as. many recipients, thus reducing production costs associated with embryos of undesirable sex.

\section{In vitro embryo production}

Techniques and procedures based on the use of in vitro fertilization technology offer significant benefits in relation to genetic improvement and reproductive management of domestic ruminants. Underlining the importance of this area and in recognition of some of the inherent problems facing users of this technology, a symposium was recently held in Orlando, Florida in conjunction with the $32^{\text {nd }}$ Annual Conference of the International Embryo Transfer Society entitled 'Realizing the promise of IVF in cattle: Optimizing embryonic and fetal survival' at which many related topics were addressed including procedures for transferring a better embryo, errors in embryonic and fetal development, recipient management and cryopreservation (Hansen 2006).

In vitro, most studies terminate at the blastocyst or hatched blastocyst stage of development. This is a reflection of two things: (i) the blastocyst stage is, in cattle at least, the stage most routinely used for transfer or cryopreservation and (ii) in vitro systems do not support normal development of ruminant embryos through the post-hatching elongation stages. Artificial elongation has been induced in vitro using agarose gel tunnels (Vajta et al. 2000; Brandao et al. 2004). While such results are encouraging, the technology still requires considerable refinement; for 
example, the embryonic disk characterizing the pre-streak stage 1 is never established (Alexopoulos et al. 2005; Vejlsted et al. 2006)

For all IVF technologies, achieving economically viable success rates is still a problem. Less than $30 \%$ of cultured oocytes develop into transferable embryos. Wastage during pregnancy is also increased with pregnancy rates from IVF embryos typically $10 \%$ lower than those achieved with in vivo embryos. From a genetic improvement point-of-view, the use of ovaries collected from random females at local abattoirs offers little in the way of genetic superiority (Cunningham 1999).

The in vitro production of ruminant embryos is a three-step process involving in vitro oocyte maturation, in vitro fertilization and in vitro culture. In terms of efficiency, in cattle, approximately $90 \%$ of immature oocytes, generally recovered from follicles at unknown stages of the oestrous cycle, undergo nuclear maturation in vitro from prophase I to metaphase II (the stage at which they would be ovulated in vivo); about $80 \%$ undergo fertilization following insemination and cleave at least once, to the two-cell stage. However, only $30-40 \%$ of such oocytes reach the blastocyst stage, at which they can be transferred to a recipient or frozen for future use. Thus, the major fall-off in development occurs during the last part of the process (in vitro culture), between the 2-cell and blastocyst stages, suggesting that post-fertilization embryo culture is the most critical period of the process in terms of determining the blastocyst yield. There is considerable evidence demonstrating the quality of the oocyte is crucial in determining the proportion of immature oocytes that form blastocysts and that the post-fertilization culture environment, within certain limits, does not have a major influence on the capacity of the immature oocyte to form a blastocyst (see Rizos et al. 2002a). It would appear that once the oocyte has been removed from the follicle its ability to develop the blastocyst stage is more-orless sealed and despite attempts at temporarily inhibiting resumption of meiosis to allow cytoplasmic maturation to proceed in vitro, thereby improving development (e.g. Lonergan et al. 2000; Sirard 2001) or modifications of maturation media, blastocyst yields in vitro using oocytes recovered from slaughtered animals rarely exceed $40 \%$ on a consistent basis. Therefore, attempts at increasing oocyte competence must be applied before removal from the follicle by manipulating follicle development (e.g., Blondin et al. 2002; Durocher et al. 2006)

\section{Ovum Pick-Up (OPU)}

OPU was first developed in cattle in the early nineties (Pieterse et al. 1991). Since then many studies have been carried out aimed at refining both technical (e.g., needle size, vacuum pressure) and biological (e.g., hormonal stimulation, frequency, operator skill) factors (reviewed by Merton et al. 2003; van Wagtendonk-de Leeuw 2006). The advent of OPU opened up significant potential for the application of IVF technology to animal breeding. Collecting the ovaries of slaughtered beef animals, while offering a fantastic source of raw material (oocytes and, after IVF, embryos) for basic research studies, had very little to offer in terms of genetic improvement; however, OPU allows the repeated access to the ovaries of high genetic merit cows and when coupled with semen from a high genetic merit sire, allows the feasibility of producing high quality embryos, genetically speaking, in large numbers. When the techniques of OPU and IVF are combined they are capable of producing 80-100 calves per donor cow per year albeit with large variation between donors (van Wagtendonk-de Leeuw 2006); this compares with typically one calf per cow per year with AI and approximately 20-25 calves per donor with MOET. 


\section{Cloning}

Since the birth of Dolly, the first mammal to be cloned using the nucleus of a somatic cell from an adult animal, in 1997 (Wilmut et al. 1997) standard somatic cell nuclear transfer (SCNT) techniques have resulted in the birth of live offspring in 11 species (Vajta \& Gjerris 2006). Although considerable variation exists the basic steps involved include (i) enucleation of an in vitro matured oocyte for use as recipient cytoplasm, (ii) insertion of donor cell/nucleus, and (iii) activation of the reconstructed embryo. A relatively new approach to nuclear transfer is the socalled handmade cloning technique which obviates the need for expensive micromanipulators. However, it does require more specialized culture conditions for reconstructed embryos as zona removal is an integral part of the process (Vajta et al. 2005).

The application of cloning techniques to animal breeding are numerous including the fact that many animals of the same genotype can theoretically be produced increasing the accuracy of evaluation (as each female can be evaluated on the average phenotypic performance of herself) and allowing the evaluation of post-slaughter traits in a cohort of clones, the exploitation of heterosis and the multiplication of transgenic animals (Cunningham 1999; Van Arendonk \& Bijma 2003). Clearly, however, the testing of clones could be problematical, especially in the case of traits of low heritability, and the risks of a reduction in genetic variation need to be considered.

One of the biggest drawbacks of this technology is the inefficiency of the process. While blastocysts can be produced at rates comparable with those of routine IVF in cattle, a very limited percentage $(0.5-5 \%)$ of the reconstructed embryos result in full term development. This is mainly due to a high frequency of postimplantation developmental arrest. Such losses are predominantly during the first trimester of pregnancy but can occur much later (Heyman et al. 2002). Heyman et al. (2002) monitored the evolution of pregnancy following the transfer of embryos derived from somatic cell cloning, embryonic cloning and IVP in order to detect the occurrence of late gestation losses and their frequency. On the basis of progesterone concentrations on Day 21, there were no significant differences in the percentages of initiated pregnancies between the groups $(55.6-62.7 \%)$. Confirmed pregnancy rate by Day 35 using ultrasound scanning was significantly lower in the two somatic cloned groups (27.5-33.8\%) compared with the embryonic clones $(49.2 \%)$ and IVF embryos $(52.9 \%)$. This pattern was maintained at Days. 50,70 and 90 . The incidence of loss between Day 90 of gestation and calving was $43.7 \%$ for adult somatic clones and $33.3 \%$ for fetal somatic clones compared with $4.3 \%$ after embryonic cloning and $0 \%$ after IVP.

\section{Long Term Consequences of Embryo Culture Conditions}

Although normal calves can result from the transfer of embryos produced in vitro or by somatic cell nuclear transfer, these embryo technologies are more often associated with increased rates of abortion and abnormal development of the fetus and placenta (Bertolini \& Anderson 2002; Farin et al. 2001; Kruip \& den Daas 1997). Several studies have shown that embryos are sensitive to environmental conditions that can affect future growth and developmental potential, both pre- and postnatally (e.g., Young \& Fairburn 2000; Fleming et al. 2004). It is well known that early ruminant embryos also exhibit sensitivity to their environment which may, after transfer, lead to the abnormal development, characterized by aberrant fetal and placental development, increased fetal myogenesis, dystocia, abnormal perinatal pulmonary activity and increased mortality in the early postnatal period (Walker et al. 1996; Sinclair et al. 2000). In 
addition, some of the effects, such as increased organ size, can persist into later life (McEvoy et al. 1998). These alterations in phenotype have been referred to as 'Large Calf Syndrome' or 'Large Offspring Syndrome' although a new term, 'abnormal offspring syndrome' has been proposed (Farin et al. 2006) to better represent the fact that abnormalities other than solely large size are observed.

It is worth bearing in mind that abnormalities in development arising from the environment to which the embryo is exposed are not limited to in vitro culture or manipulation. Maternal diet can impact preimplantation phenotype and long-term development. For example, high protein diets in sheep around conception have been associated with reduced viability and increased fetal and birth weights (McEvoy et al. 1997; 2001) as well as alterations in fetal development and physiology (Edwards \& McMillen 2002; McMillen \& Robinson 2005).

Collectively these in vivo and in vitro studies support the notion that the environment of the embryo is critical for its future. The identification and characterization of the short-term effects of in vitro culture raises the question about long-term consequences and safety of assisted reproductive technologies. For example, recent reports indicate that in vitro culture of mouse embryos can have irreversibly long-term consequences of postnatal development, growth, physiology, and behaviour in resulting offspring (Ecker et al. 2004; Fernandez-Gonzales et al. 2004)

\section{Conclusions}

As pointed out by Cunningham (1999), the baseline against which all new reproductive and genetic methods must be measured is natural service. The use of a stock bull by an individual farmer has a certain cost and convenience associated with it. For example, in Ireland Al usage in cattle has declined by approximately $20 \%$ over the past 5 years. The reasons for the decline are related to the labour availability required for $\mathrm{Al}$ and a perceived lack of benefit (Buckley et al. 2003). This is despite a recent objective analysis which demonstrated that daughters of relatively high Economic Breeding Index bulls leave on average 80 euro profit per lactation more than those of stock bulls (Berry et al. 2005). Therefore, new technologies, or refinement of existing ones, must take into account the demands of the end-user to ensure they are taken up in practice. As indicated by van Wagtendonk-de Leeuw (2006) not many breakthroughs are expected for OPU technology in the near future. Advances in IVP technology and our understanding of the factors controlling embryo development may allow the development of in vitro culture systems which can produce embryos of a quality similar to those produced in vivo which ultimately would lead to improved quality and welfare of subsequent offspring.

\section{Acknowledgements}

The author's research is funded in part by Science Foundation Ireland (Grant 02/IN1/B78). The opinions, findings and conclusions or recommendations expressed in this material are those of the author and do not necessarily reflect the views of the Science Foundation Ireland.

\section{References}

Alexopoulos NI, Vajta G, Maddox-Hyttel P, French A), \& Trounson AO 2005 Stereomicroscopic and histological examination of bovine embryos follow. ing extended in vitro culture. Reproduction Fertility and Development 17 799-808
Berry D, Cromie A, Coughlan S, Dillon P 2005 An objective comparison of artificial insemination and the stock bull in Irish dairy herds. Published online: www.icbf.com. 
Bertolini M \& Anderson GB 2002 The placenta as a contributor to production of large calves. Theriogenology 57 181-187.

Besenfelder U \& Brem G 1998 Tubal transfer of bovine embryos: a simple endoscopic method reducing long term exposure of in vitro produced embryos. Theriogenology 50 739-745

Besenfelder U, Havlicek V, Mösslacher G \& Brem G 2001 Collection of tubal stage bovine embryos by means of endoscopy. A techrique report. Theriogenology 55 837-845.

Boland MP, Goulding D \& Roche JF 1991 Alternative gonadotrophins for superovulation in cattle. Theriogenology 35 5-17.

Blondin P, Bousquet D, Twagiramungu H, Barnes F \& Sirard MA 2002 Manipulation of follicular development to produce developmentally competent bovine oocytes, Biology of Reproduction 66 38-43.

Brandao DO, Maddox-Hyttel P, Lovendahl P, Rumpf R, Stringfellow D, \& Callesen H 2004 Post hatching development: a novel system for extended in vitro culture of bovine embryos. Biology of Reproduction 71 2048-2055.

Buckley F, Mee I, Sullivan K, Evans R, Berry D, Dillon P 2003 Insemination factors affecting the conception rate in seasonal calving Holstein-Friesian cows. Reproduction. Nutrition Development 43 543-555.

Cunningham EP 1999 The application of biolechnologies to enhance animal production in different farming systems. Livestock Production Science 58 1-24.

Durocher J, Morin N \& Blondin P 2006 Effect of hormonal stimulation on bovine follicular response and oocyle developmental competence in a commercial operation. Theriogenology 65 102-115.

Ecker, DJ, Stein P, Xu Z, Williams CJ, Kopf GS, Biker WB, Abel T \& Schultz RM 2004 Long-term effects of culture of preimplantation mouse embryos on behavior. Proc Natl Acad Sci USA 101 1595-1600.

Eckert J \& Niemann H 1998 mRNA expression of leukaemia inhibitory factor (Lif) and its receptor subunits glycoprotein 130 and Lif-receptor-beta in bovine embryos derived in vitro or in vivo. Molecular Human Reproduction 4 957-965.

Edwards LJ \& McMillen IC 2002 Impact of maternal undernutrition during the periconceptional period, fetal number and fetal sex on the development of the hypothalamo-pituitary adrenal axis in sheep during late gestation. Biology of Reproduction 661562 . 1569.

Enright BP, Lonergan P, Dinnyes A, Fair T, Ward FA, Yang X Boland MP 2000 Culture of in vitro produced bovine zygotes in vitro $v$ s in vivo: implications for early embryo development and quality. Theriogenology 54 659-673.

Evans G, Hollinshead FK \& Maxwell WMC 2004 Preservation and artificial insemination of sexed semen in sheep. Reproduction Fertility and Development 16 455-464.

Fair T, Murphy M, Rizos D, Moss C, Martin F, Boland MP \& Lonergan P 2004 Analysis of differential maternal mRNA expression in developmentally com- petent and incompetent bovine two-cell embryos Molecular Reproduction and Development 67136 144.

Farin PW, Crosier AE \& Farin CE 2001 Influence of in vitro systems on embryo survival and fetal development in cattle. Theriogenology 55 151-170.

Farin PW, Piedrahita \& Farin CE 2006 Errors in development of fetuses and placentas from in vitro-produced bovine embryos. Theriogenology 65 178-91.

Fernández-Gonzalez $\mathrm{R}$, Moreira $\mathrm{P}$, Bilbao $\mathrm{A}$, liménez A, Pérez-Crespo M, Ramírez MA, Rodríguez De Fonseca F, Pintado B \& Gutiérrez-Adán A 2004 Long term effect of in vitro culture of mouse embryos with serum on mRNA expression of imprinting genes, development, and behavior. Proceedings of the National Academy of Sciences of the United States of America 101 5880-5885.

Fleming TP, Kwong WY, Porter R, Ursell E, Fesenko I, Wilkins A, Miller DJ, Watkins AJ \& Eckert JJ 2004 The embryo and its future. Biology of Reproduction 71 1046-1054.

Galli C \& Lazzari G 1996 Practical aspects of IVM/IVF in cattle. Animal Reproduction Science 42 371-379.

Galli C \& Lazzari G 2005 Embryo technologies in dairy cattle. $26^{\text {th }}$ European Holstein and Red Holstein Conference, Prague.

Georges M \& Massey JM 1991 Velogenetics, or the synergistic use of marker assisted selection and germline manipulation. Theriogenology 35 151-159.

Hansen PJ 2006 Realizing the promise of IVF in cattle an overview. Theriogenology 65 119-125.

Harvey AJ, Kind KL., Pantaleon M, Armstrong DT \& Thompson JG 2004 Oxygen-regulated gene expression in bovine blastocysts. Biology of Reproduction 71 1108-1119.

Hasler JF 2003 The current status and future of commercial embryo transfer in cattle. Animal Reproduction Science 79 245-264.

Heyman Y, Chavette-Palmer P, LeBourhis D, Camous S, Vignon X \& Renard JP 2002 Frequency and occurrence of late-gestation losses from cattle cloned embryos. Biology of Reproduction 66 6-13.

Hollinshead FK, Evans G, Evans KM, Catt SL, Maxwell WMC, O'Brien JK 2004 Birth of lambs of a predetermined sex after in vitro production of embryos using frozen-thawed sex-sorted and re-frozen-thawed ram spermatozoa. Reproduction 127 557-568.

Kind KL, Collett RA, Harvey AJ \& Thompson JG 2004 Oxygen-regulaled expression of GLUT-1, GLUT-3 and VEGF in the mouse blastocyst. Molecular Reproduction and Development 70 37-44.

Kruip TAM \& den Daas JHG 1997 In vitro produced and cloned embryos: effects on pregnancy, parturition and offspring. Theriogenology 47 43-52.

Lazzari G, Wrenzycki C, Herrmann D, Duchi R, Kruip T, Niemann H \& Galli C 2002 Cellular and molecular deviations in bovine in vitro-produced embryos are related to the large offspring syndrome. Biology of Reproduction 67 767-775.

Lohuis MM 1995 Potential benefits of bovine embryo manipulation technologies to genetic improvement 
programs Theriogenology 43 51-60.

Lonergan $\mathbf{P}$, Khatir $\mathbf{H}$, Piumi F, Rieger D, Humblot $\mathbf{P}$, Boland MP 1999 Effect of time interval from insemination to first cleavage on the developmental characteristics, sex ratio and pregnancy rate after transfer of bovine embryos. Joumal of Reproduction and Fertility 117 159-67.

Lonergan P, Dinnyes A, Fair T, Yang X \& Boland MP 2000 Bovine oocyte and embryo development following meiotic inhibition with butyrolactone I. Molecular Reproduction and Development 57 204-209.

Lonergan P, Rizos D, Gutierrez-Adan A, Fair T \& Boland MP 2003a Oocyle and embryo quality: effect of origin, culture conditions and gene expression patterns. Reproduction in Domestic Anima/s 38 259-267.

Lonergan P, Rizos D, Gutierrez-Adan A, Moreira P, Pintado B, de la Fuente J \& Boland MP 2003b Temporal divergence in the pattern of messenger RNA expression in bovine embryos cultured from the zygote to blastocyst stage in vitro or in vivo. Biology of Reproduction 69 1424-1431.

Lonergan P, Fair T, Corcoran D \& Evans AC 2006 Effect of culture environment on gene expression and developmental characteristics in IVF-derived embryos. Theriogenology 65 137-152.

Looney CR, Nelson JS, Schneider HJ \& Forrest DW 2006 Improving fertility in beef cow recipients, Theriogenology 65201-209.

Lu KH, Cran DG \&Seidel GE 1999 In vitro fertilization with flow-cytomeirically sorted bovine sperm. Theriogenology 52 1393-1405.

McEvoy TG, Robinson II, Aitken RP, Findlay PA, Robertson IS 1997 Dietary excesses of urea influence the viability and metabolism of preimplantation sheep embryos and may affect felal growth among survivors. Animal Reproduction Science 47 71-90.

McEvoy TG, Sinclair KD, Broadbent PJ, Goodhand KL \& Robinson JJ 1998 Post-natal growth and development of Simmental calves derived from in vivo or in vitro embryos. Reproduction Fertility and Development 10 459-464.

McEvoy TG, Robinson II, Ashworth CJ, Rooke JA \& Sinclair KD 2001 Feed and forage toxicants affecting embryo survival and fetal development. Theriogenology 55 113-129.

McMillen IC \& Robinson IS 2005 Developmental origins of the metabolic syndrome: prediction, plasticity, and programming. Physiological Reviews $\mathbf{8 5}$ 571-633.

Maxwell WMC, Evans G, Hollinshead FK Bathgate $R$ De Graff SP, Eriksson BM, Gillian L, Morton KM \& O'Brien JK 2004 Integration of sperm sexing technology into the ART toolbox. Animal Reproduction Science 82-83 79-95.

Merton JS, de Roos AP, Mullaart E, de Ruigh L, Kaal L, Vos PL, Dieleman SJ 2003 Factors affecting oocyfe quantity in commercial application of embryo technologies in the cattle breeding industry. Theriogenology 59 651-674.
Morton KM, Catt SL, Hollinshead FK, Maxwell WM \& Evans G 2004 Production of lambs after the transfer of fresh and cryopreserved in vitro produced embryos from prepubertal lamb oocytes and unsorted and sex-sorted frozen-thawed spermatozoa. Reproduction in Domestic Animals 39 454-61.

Natale DR, De Sousa PA, Westhusin ME \& Watson A] 2001 Sensitivity of bovine blastocyst gene expression patterns to culture environments assessed by differential display RT-PCR. Reproduction 122 687693.

Nicholas FW 1996 Genetic improvement through reproductive technology Animal Reproductive Science 42 205-214.

Pieterse MC, Vos PLAM, Kruip TAM, Wurth YA, van Beneden ThH, Willemse AH Taverne MA 1991 Transvaginal ultrasound-guided follicle aspiration of bovine oocytes. Theriogenology 35 19-24.

Rexroad CE \& Powell AM 1999 The ovine uterus as a host for in vitro-produced bovine embryos. Theriogenology 52 351-364.

Rinaudo P \& Schultz RM 2004 Effects of embryo culture on global pattern of gene expression in preimplantation mouse embryos. Reproduction 128301 311.

Rizos D, Lonergan P, Ward F, Duffy P \& Boland MP 2002 a Consequences of bovine oocyte maturation, fertilization or early embryo development in vitro versus in vivo: implications for blastocyst yield and blastocyst quality. Molecular Reproduction and Development 61 234-248.

Rizos D, Lonergan P, Boland MP, Arroyo-Garcia R, Pintado B, de la Fuente J, Gutierrez-Adan A 2002b Analysis of differential mRNA expression belween bovine blastocysts produced in different culture systems: Implications for blastocyst quality. Biology of Reproduction 66 589-595.

Schenk JL, Suh TK, Seidel Jr \& GE 2006 Embryo production from superovulated cattle following insemination of sexed sperm Theriogenology 65 299-307.

Seidel GE Jr \& Garner DL 2002 Current status of sexing mámmalian spermatozoa. Reproduction 124733 43.

Seidel GE Jr 2003a Sexing mammalian sperm-intertwining of commerce, technology, and biology. Animal Reproduction Science 79 145-56.

Seidel GE Jr $2003 \mathrm{~b}$ Economics of selecting for sex: the most important genetic trait. Theriogenology 59585 98.

Sinclair KD, Young LE, Wilmut I \& McEvoy TG 2000 In-utero overgrowth in ruminants following embryo culture: lessons from mice and a warning to men. Human Reproduction 15(Suppl. 5) 68-86.

Sirard MA 2001 Resumption of meiosis: mechanism involved in meiotic progression and its relation with developmental competence. Theriogenology 55 1241-1254.

Taneja M, Bols PE, Van de Velde A, Ju IC, Schreiber D, Tripp MW, Levine H, Echelard Y, Riesen I, Yang X 2000 Developmental competence of juvenile calf oocyles in vitro and in vivo: influence of donor ani- 
mal variation and repeated gonadotropin stimulation. Biology of Reproduction 62206213.

Thibier M 2005 International Embryo Transfer Sociely: Dala Retrieval Committee Annual Report. Embryo Transfer Newsletter 22 12-19.

Vajta G, Hyttel P \& Trounson A 2000 Post-hatching development of in vitro produced bovine embryos on agar or collagen gels. Animal Reproduction Science 60-61 208.

Vajta G \& Gjerris M 2006 Science and technology of farm animal cloning: state of the art. Animal Reproduction Science 92 211-230.

Vajta G, Kragh PM, Mtango NR \& Callesen H 2005 Handmade cloning approach: potentials and limilations. Reproduction, Fertility and Development 17 97-112.

Van Arendonk IAM \& Bijma P 2003 Factors affecting commercial application of embryo technologies in dairy cattle in Europe - a modeling approach. Theriogenology $59 \quad 635-649$.

Van Soom A, Mateusen B, Leroy J \& De Kruif A 2003 Assessment of mammalian embryo quality: what can we learn from embryo morphology? Reproductive Biomedicine Online 7 664-70.

Van Wagtendonk-de Leeuw AM 2006 Ovum pick up and in vitro production in the bovine after use in several generations: A 2005 status. Theriogenology 65 914-925.

Vejlsted M, Du Y, Vajta G \& Maddox-Hyttel P 2006 Post-hatching development of the porcine and bovine embryo-defining criteria for expected development in vivo and in vitro. Theriogenology 65 153-65.
Walker SK, Hartwich KM \& Seamark RF 1996 The production of unusually large offspring following embryo manipulation: concepts and challenges. Theriogenology 45 111-120.

Walmsley SC, Buckrell BC, Buschbeck C, Rumph N \& Pollard JW 2004 Rate of abnormalities in lambs from in vilro produced embryos Iransferred on Day 2 compared with Day 6 postfertilization. Theriogenology 62 195-206.

Wetscher F, Havlicek V, Huber T, Gilles M, Tesfaye D, Griese J, Wimmers K, Schellander K, Müller M, Brem G \& Besenfelder U 2005 Intrafallopian transfer of gametes and early stage embryos for in vivo culture in caltle. Theriogenology 64 30-40.

Wheeler MB, Rutledge II, Fischer-Brown A, VanEtten T, Malusky S, \& Beebe DJ 2006 Application of sexed semen technology to in vitro embryo production in cattle. Theriogenology 65 219-227.

Wilmut I, Schnieke AE, McWhir J, Kind AJ \& Campbell $\mathrm{KH} 1997$ Vital offspring derived from adult and adult mammalian cells. Nature 385 810-813.

Wrenzycki C, Herrmann D, Lucas-Hahn A, Korsawe K, Lemme E \& Niemann H 2005 Messenger RNA expression patterns in bovine embryos derived from in vitro procedures and their implications for development. Reproduction, Fertility and Development 17 23-35.

Young IE \& Fairburn HR 2000 Improving the safety of embryo technologies: possible role of genomic imprinting. Theriogenology $53627-648$. 